\title{
ENSINANDO SOBRE ADULTERAÇÃO DO LEITE: RELATO DE UMA EXPERIÊNCIA UTILIZANDO MATERIAIS ALTERNATIVOS
}

Originais recebidos em: 27/09/2010

Aceito para publicação em: 18/08/2011

João Rufino de Freitas Filho

Vânia Albino Macário Lima

Rodrigo da Silva Lima

Mábio Silvan José da Silva

Carlos Alexandre Silva de Melo

Daniele Santos de Oliveira

Universidade Federal Rural de

Pernambuco/Unidade Acadêmica de

Garanhuns

joaoveronice@yahoo.com.br

João Rufino de Freitas Neto

Faculdade Maurício de Nassau

Erro! Fonte de referência não encontrada.

Este trabalho foi conduzido com o objetivo de se utilizarem materiais alternativos na detecção de substâncias estranhas presentes no leite de vaca consumido por estudantes de escolas públicas de Garanhuns/PE. O projeto foi conduzido durante um período de 90 dias, dividido em cinco etapas: I - estudo dos estabelecimentos de ensino objeto de estudo; II - visita in loco; III - pesquisa experimental; IV - demonstração em sala de aula; e V - elaboração e divulgação de jornal e cartilha informativa.

Palavras-chave: Zootecnia. Leite Qualidade e Consumo. Substâncias estranhas. Cartilha informativa. Ensino Médio e Fundamental.

\section{TEACHING ABOUT ADULTERATION} OF MILK: AN EXPERIENCE REPORT USING ALTERNATIVE MATERIALS

\section{Abstract}

This work was conducted out with the objective of using alternative materials in the detection of strange substance present in the milk of cows consumed by students in public schools Garanhuns / PE. The project was conducted during a period of 90 days, was divided in five etage follows: I - Study of schools object of study; II visit in locus; III - experimental research; IV - demonstration in the classroom and Vdevelopment and dissemination newsprint and book information.

Keywords: Animal Production. Milk Quality and Consumption. Strange substance. Informative booklet - High school and Elementary.

\section{CONSIDERAÇÕES INICIAIS}

O leite é definido como o produto integral não alterado nem adulterado, sem colostro e proveniente de uma ordenha higiênica, completa e ininterrupta das fêmeas saudáveis e bem alimentadas (ORDÓNEZ, 2005). 
É um alimento que facilmente pode ser fraudado, com acréscimo de água por alguns produtores, preocupados em aumentar suas margens financeiras e lesando o consumidor que paga por um produto e consome outro.

Além de ser um alimento com grande valor nutricional e muito importante no crescimento dos mamíferos, atualmente o leite é um dos principais alimentos consumidos mundialmente; é aceito praticamente por todos. O consumo de leite e derivados cresce em todo o mundo, até mesmo no Brasil, gerando com isso impacto na economia mundial (PEDRAS, 2007).

O leite é um alimento consumido principalmente por crianças em fase de crescimento e alfabetização, representando uma importante fonte de energia (SILVA et al., 2009).

A qualidade dos alimentos se tornou um problema mundial, e é cada vez mais importante detectar a introdução no mercado de produtos rotulados de forma fraudulenta e de qualidade inferior, por razões econômicas e por razões de saúde pública (EGITO et al., 2006).

O leite precisa ser submetido, na indústria, à elevação de temperatura, para eliminar os agentes causadores de doenças, garantindo também a sua conservação. Nesse sentido, é importante alertar que esse alimento só deve ser consumido após ser pasteurizado na indústria. Não se recomenda a compra do produto diretamente das propriedades rurais, sem ter sido submetido a altas temperaturas (pasteurização), pois pode transmitir doenças.

A quantidade e qualidade do leite produzida e sua composição apresentam variações ocasionadas por diversos fatores: espécie, raça, fisiologia, alimentação, estação do ano, doenças, período de lactação, ordenhas, fraudes e adulterações (SILVA, 1997).

O processo de modernização no setor leiteiro em algumas regiões do Brasil, com significativas mudanças nos sistemas de armazenamento e transporte do leite, como a adoção do resfriamento do leite na fazenda, logo após a ordenha, e a posterior coleta e transporte do produto em caminhões-tanque isotérmicos têm ocasionado danos à qualidade do produto por atuar de forma seletiva na presença de psicrotróficos. Além disso, algumas falhas higiênicas durante a produção podem ser mascaradas com essa prática, especialmente aquelas relacionadas à presença e ao desenvolvimento de microrganismos mesófilos (SOARES, 2004).

O leite é considerado o mais completo alimento, possuindo elevado valor biológico na alimentação humana. Seus elementos nutricionais, sobretudo proteínas, lipídeos, carboidratos, 
vitaminas e minerais, tornam o leite, porém, excelente substrato para o crescimento de microrganismos. Desse modo, o leite deve ser obtido com a máxima higiene e mantido em baixa temperatura, desde a ordenha até a ocasião de seu beneficiamento, no sentido de garantir as características físicas, químicas e nutricionais do produto distribuído para consumo. A adoção de práticas fraudulentas, como a adição de água ao leite, também afeta as suas propriedades, as quais podem ser facilmente verificadas através de exames laboratoriais.

Dessa forma, a constante avaliação da qualidade do leite se faz então necessária e o conhecimento da composição de seus principais constituintes, obtido através de análises físico-químicas, permite avaliar o seu valor nutricional e tecnológico e detectar a possível ocorrência de fraude (BEHMER, 1984). No entanto, a adição de soro ao leite é de difícil detecção, por ser um constituinte natural do leite, afetando por igual todas as suas características físico-químicas (SOARES; RAMOS, A.; RAMOS, E., 2005).

Os casos de fraudes ocorrem no momento em que o leite é ordenhado, geralmente, antes de ser encaminhado para o laticínio. Entende-se por falsificação a adição ou subtração parcial ou total de qualquer substância na composição do produto. A falsificação é o delito resultante da desnaturação de um produto, visando tirar lucro ilícito, isto é, lesar e enganar, seja por adição de uma matéria qualquer que não exista no produto ou pela subtração de um dos seus elementos, em condições tais que não corresponda ao produto normal. As fraudes mais generalizadas são - o adicionamento de água ao leite, desnatação parcial ou adição de leite desnatado e, ainda, o adicionamento de água e leite desnatado conjuntamente (BEHMER, 1999).

A qualidade do leite consumido no país é uma constante preocupação de técnicos e autoridades ligadas à área de saúde e laticínios (CARVALHO et al., 2007).

Tendo em vista o grande consumo do leite e a sua importância como um alimento de famílias de diversos níveis sociais, o presente projeto teve como objetivos:

prestar informações à comunidade estudantil e comunidade em geral sobre a qualidade de leite consumido;

avaliar o nível de aceitação do leite por estudante de escolas públicas;

construir materiais alternativos para análise do leite;

identificar substâncias estranhas presentes no leite in natura comercializado em pequeno estabelecimento comercial; 
$\square$ propor metodologia simples para teste do leite;

identificar quais substâncias estranhas estão presente no leite fornecido na merenda escolar dos estudantes.

\section{MATERIAL E MÉTODOS}

O projeto foi desenvolvido na cidade de Garanhuns (PE), com a colaboração/participação de dois estudantes de graduação em Zootecnia e três do Ensino Médio, sob a coordenação de dois profissionais habilitados, um professor de Química e uma Zootecnista. O experimento foi realizado em 90 dias (maio/2006 a agosto/2007) e foi dividido em cinco etapas: I - seleção dos estabelecimentos de ensino objeto de estudo; II - visita in loco aos estabelecimentos de ensino; III - pesquisa experimental em laboratório pelos alunos extensionistas; IV - demonstração em sala de aula; e V - elaboração e divulgação de jornal e cartilha informativa.

\section{I - Seleção dos estabelecimentos de ensino objeto de estudo}

Este estudo foi conduzido primeiramente através de uma consulta à Gerência Regional de Educação (GRE) para identificação de Escolas de sua jurisdição. O processo seletivo considerou os seguintes critérios: localização, modalidade de ensino, fornecimento de leite na merenda escolar, classe social dos estudantes e da comunidade em que a escola está inserida.

\section{II - Visita in loco aos estabelecimentos de ensino}

Do processo anterior foram selecionadas quatro escolas (3 de ensino fundamental e 1 de ensino médio) que foram visitadas a campo: Escola Estadual Jerônimo Gueiros, Escola Elisa Coelho, Escola Henrique Dias e Escola Dom Juvêncio de Brito. Nas visitas, foram realizadas entrevistas com alunos, professores e gestores. Também foram realizadas visitas quinzenais a estabelecimentos comerciais (mercearia, padaria, supermercado etc.) e, em cada visita, foi realizada entrevista com proprietários e coleta de amostra de leite para análise.

\section{III - Pesquisa Experimental em Laboratório pelos alunos extensionistas}


Esta etapa foi realizada no laboratório da Escola Estadual Professor Jerônimo Gueiros e Laboratório de Química da Universidade Federal Rural de Pernambuco/Unidade Acadêmica de Garanhuns (UFRPE/UAG). Para análises do leite, foram construídos equipamentos com materiais alternativos e elaborados procedimentos experimentais, antes da sistematização e operacionalização nas escolas escolhidas.

A parte laboratorial foi conduzida de acordo com as metodologias descritas nas literaturas (FREITAS FILHO et al., 2009; PINA et al., 2007; PEREIRA et al., 2001; SILVA, 1997).

\section{IV - Demonstração Experimental em sala de aula}

Esta etapa foi desenvolvida em salas de aula das escolas selecionadas. Na elaboração e execução dos experimentos pelos estudantes extensionistas, foram utilizados materiais descartáveis (materiais do cotidiano dos alunos), de fácil aquisição, tais como quenga de coco e mão de pilão, garrafas PET, água oxigenada, papoula, iodeto de potássio, tintura de iodo, vinagre, soda cáustica, pano, vidro de maionese, vidro de alimentação infantil, fogão, panelas, detergente, entre outros.

\section{V - Elaboração e divulgação de jornal e cartilha informativa}

Através dos dados dos estudos realizados, foram elaboradas cartilhas informativas e jornais impressos, com o objetivo de conscientizar a população quanto à importância do consumo de leite de boa qualidade, principais fraudes, micoorganismos presentes e doenças provocadas pelo consumo de leite de má qualidade. Os jornais e cartilhas foram distribuídos e divulgados em escolas, na comunidade em que a escola estava inserida, e em Feiras de Ciência, Bancada de Ciência e Encontro de Extensão Universitária, como objeto de estudo.

\section{RESULTADOS E ANÁLISE}

Segundo o Ministério da Agricultura e Abastecimento, a qualidade do leite é controlada pelos Institutos de Saúde Pública por meio de testes específicos que envolvem a determinação de densidade, teor de gordura, rancidez, acidez, presença de aditivos usados para conservação ou materiais estranhos ao leite para esconder o seu "batismo" com água 
(LISBOA; BOSSOIANI, 1997). Logo o presente projeto foi desenvolvido na perspectiva de conscientização, contextualização e formação de cidadãos, de modo que professores, alunos e comunidade em geral pudessem intervir de forma consciente e mais ativamente na sua realidade. $\mathrm{O}$ esquema apresentado na Figura 1 sumariza os eixos norteadores no estudo da temática do projeto.

A temática foi trabalhada na perspectiva de:

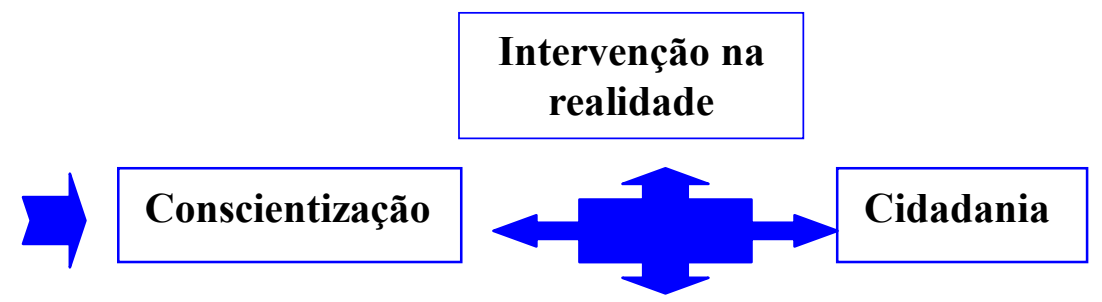

\section{Contextualização}

Figura 1: Eixos norteadores no estudo da temática do projeto

O trabalho teve início com uma pesquisa de campo cujas perguntas-chave foram as seguintes: "Esta instituição oferece leite como merenda escolar?" O leite oferecido é de boa qualidade? Dos 160 alunos entrevistados, 92\% responderam que a instituição oferece leite na merenda escolar (Gráfico 1).

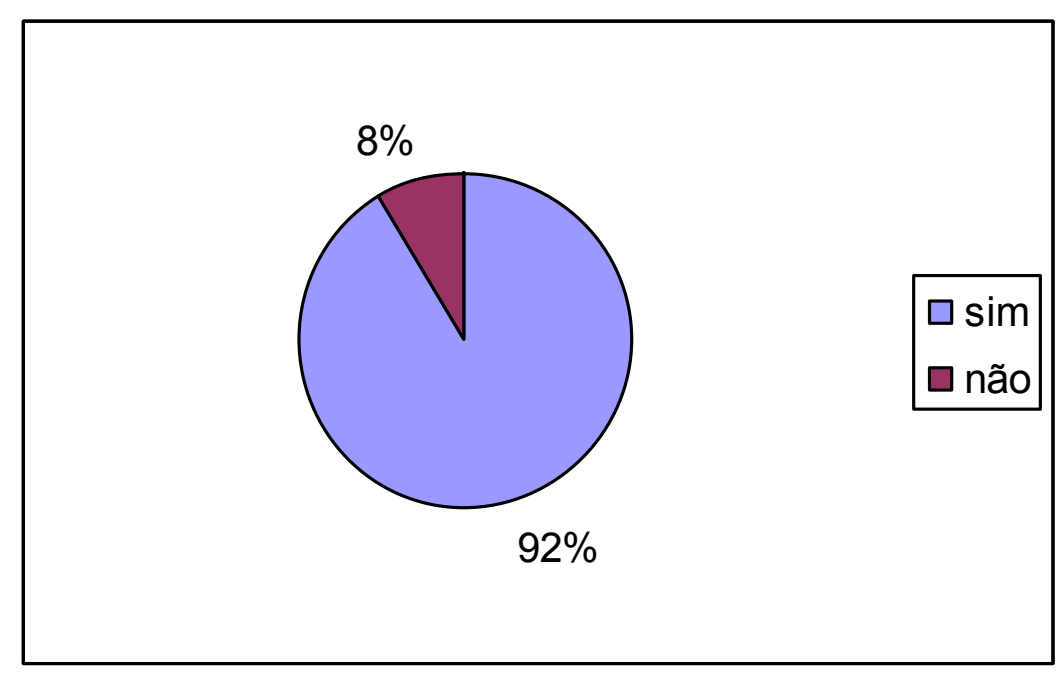

Gráfico 1: Instituição oferece leite 
Com relação à pergunta: O leite oferecido é de boa qualidade? 39\% dos estudantes responderam que não e $61 \%$ responderam que sim, conforme resultados expressos no Gráfico 2.

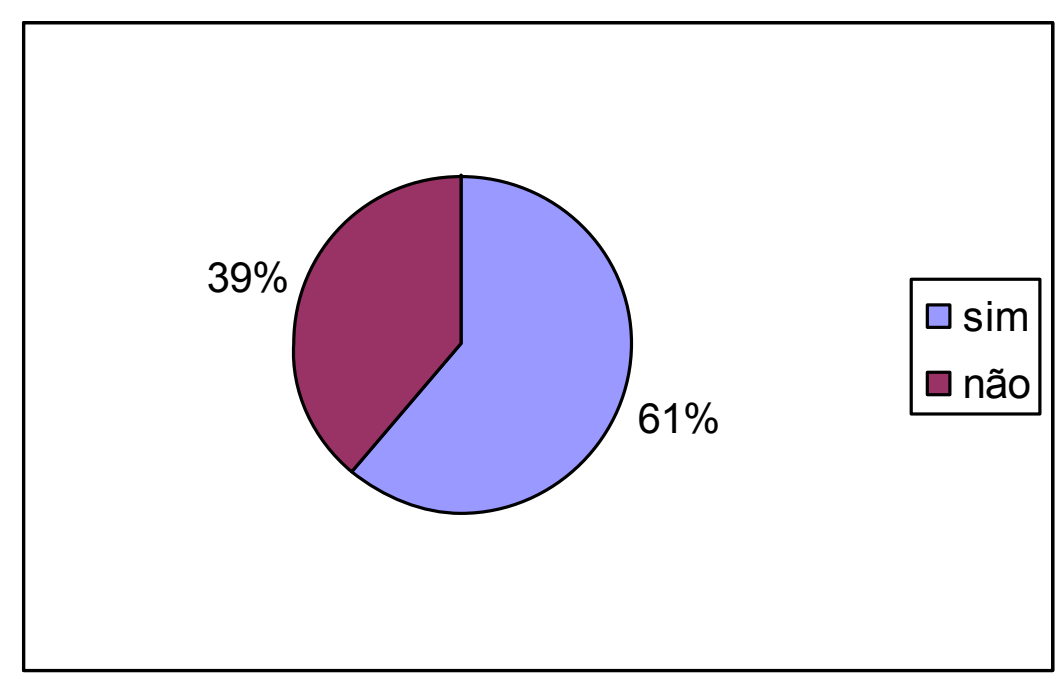

Gráfico 2: Leite de boa qualidade

Diante dos resultados obtidos das entrevistas e questionários no ambiente escolar, mas especificamente em sala de aula, passamos a outra etapa do estudo que foi a pesquisa experimental. O desenvolvimento da pesquisa experimental foi realizado em três etapas: I construção de materiais alternativos; II - elaboração de procedimentos experimentais para análise físico-químicas do leite; III - testagem dos materiais construídos e procedimentos experimentais, em sala de aulas.

\section{I-Construção de materiais alternativos}

$\mathrm{Na}$ construção dos equipamentos, foram utilizados os seguintes materiais: quenga de coco, mão de pilão, garrafas PET, fogão, panelas, vidro de maionese $(500 \mathrm{ml})$, vidro de alimentação infantil $(100 \mathrm{ml})$, seringa descartável, cordão, lata de leite ninho e outros. Os equipamentos construídos são mostrados na Figura 2. 


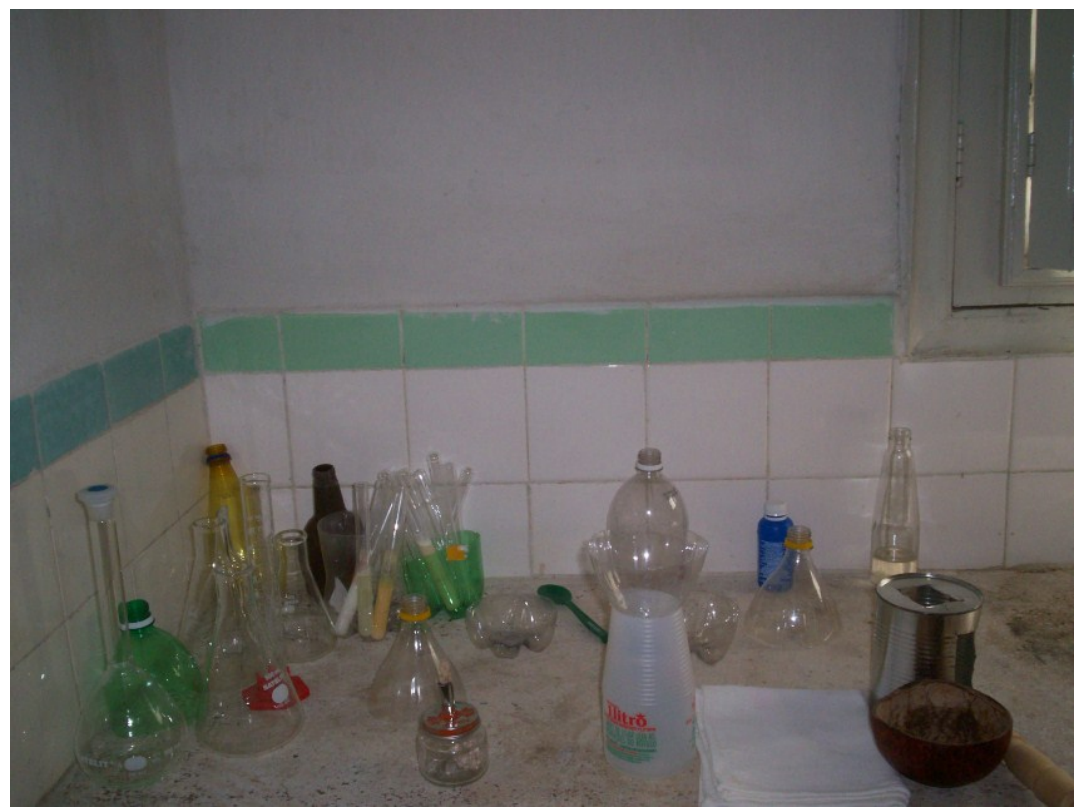

Figura 2: Materiais Construídos

\section{II - Elaboração de procedimentos experimentais}

Para analisar o leite consumido pelos alunos, foram elaborados os procedimentos experimentais abaixo:

\section{a) Determinação do teor de proteínas}

Colocaram-se mais ou menos $200 \mathrm{ml}$ de leite em um vidro de maionese $(500 \mathrm{ml}) \mathrm{e}$ aqueceu-se o leite até ficar morno, mas sem ferver. Em seguida, retirou-se o vidro do fogo e, com auxílio de uma seringa descartável, acrescentaram-se aos poucos $10 \mathrm{ml}$ de vinagre. Após adição do vinagre, houve formação de grumos de um material branco. Este foi filtrado e obteve-se a caseína. O segundo passo consistiu na obtenção da albumina, a qual foi isolada da seguinte maneira, pegou-se o soro resultante do primeiro passo e aqueceu-se até fervura. Após cinco minutos de fervura, verificou-se a formação de grumos que foi identificada como outra proteína do leite: a albumina. O soro obtido foi utilizado para análise de substâncias estranhas. As substâncias utilizadas na elaboração dos procedimentos experimentais foram as seguintes: soda cáustica, vinagre, limão, leite magnésia, solução de iodeto de potássio, tintura de iodo, álcool etílico, leite in natura e industrializado, detergente, água oxigenada, $\mathrm{FeCl}_{3}$ (encontrado em lojas de materiais eletrônicos com o nome de percloreto de ferro), entre outros. 


\section{b) Determinação da acidez do leite}

Coletaram-se flores de papoula (Hebiscus rosa-sinensis L.), em seguida as flores foram picadas em pedaços pequenos e foram adicionados $10 \mathrm{ml}$ de álcool etílico. A mistura foi macerada, em uma quenga de coco, com auxílio de uma mão de pilão, por 5 minutos. Após esse período, a mistura foi filtrada com pedaço de pano em funil construído com gargalo de garrafa PET e, em seguida, a fase aquosa do filtrado foi utilizada para teste da acidez do leite. A acidez foi realizada pela titulação do leite com de hidróxido de sódio $0,1 \mathrm{~N}$ com indicador fenolftaleína a $1 \%$. A metodologia foi a seguinte: adicionar $10 \mathrm{ml}$ da amostra +10 $\mathrm{ml}$ de água destilada +1 do extrato extraído da papula em um frasco de maionese. Em seguida titulou-se, com auxílio de uma seringa, $0,1 \mathrm{ml} / 1$ de hidróxido de sódio $(\mathrm{NaOH})$. Cada $0,1 \mathrm{ml}$ titulado correspondeu a $1{ }^{0} \mathrm{D}$.

\section{c) Teste de amido}

Com auxílio de uma seringa descartável, foram colocados $10 \mathrm{ml}$ de leite em um vidro de alimentação infantil (100 ml) e aqueceu-se ligeiramente. Acrescentaram-se cinco a seis gotas de solução de iodo para verificar se o leite continha amido, pois, nesse caso, aparece uma coloração, que pode ser azul, roxa ou quase preta. Essa coloração deve-se à formação de um complexo de amido e iodo.

\section{d) Teste de ácido salicílico}

Em frasco de vidro de $100 \mathrm{ml}$, acrescentaram-se, em cerca de $10 \mathrm{ml}$ de soro, quatro a cinco gotas de solução de cloreto de ferro (III), o qual é encontrado em lojas de materiais eletrônicos com o nome de percloreto de ferro. O aparecimento de uma coloração que vai do rosa até o violeta indicou a presença do ânion salicilato.

\section{e) Teste de ácido bórico}

Acrescentou-se cerca de três gotas do extrato de papoula a $10 \mathrm{ml}$ de leite (em um frasco de vidro de $100 \mathrm{ml}$ ). Juntou-se gota a gota a solução de $\mathrm{NaOH} 0,1 \mathrm{~mol} / 1$ até o aparecimento de uma leve cor verde. Acrescentou-se então $1 \mathrm{ml}$ de glicerina. Se a cor verde desaparecer, pode ser indício da presença de ácido bórico. Isso porque o $\mathrm{H}_{3} \mathrm{BO}_{3}$, que é ácido 
muito fraco em soluções aquosas, apresenta maior grau de ionização em glicerina, o suficiente para fazer desaparecer a coloração verde.

\section{f) Teste de peróxido}

Colocaram-se $10 \mathrm{ml}$ de leite em um vidro de alimentação infantil $(100 \mathrm{ml})$ e acrescentaram-se três a quatro gotas de detergente neutro. Em seguida, foram colocadas dez gotas de iodeto de potássio a fim de verificar se o leite continha peróxido, pois, nesse caso, aparece uma espuma no recipiente. $O$ detergente foi utilizado para demonstrar $o$ desprendimento do gás em forma de espuma.

\section{g) Teste de formol}

Em um frasco de vidro de $100 \mathrm{ml}$ contendo $10 \mathrm{ml}$ de leite, adicionou-se $1 \mathrm{ml} \mathrm{de}$ floroglucina a 1\%. Homogeneizou-se e adicionaram-se posteriormente $2 \mathrm{ml}$ de hidróxido de sódio a $10 \%$.

\section{III - Testagem dos materiais construídos e procedimentos em sala de aulas.}

\section{a) Em laboratório}

A fraude pode ser detectada com base no comportamento da acidez do leite, quando houve uma redução, foi proveniente da adição de água, e quando houve aumento, existiu desnatamento.

Nenhuma das amostras analisadas apresentaram resultados positivos nos testes de identificação de ácido salicílico e ácido bórico, os quais têm função de conservar o leite evitando a ação de microorganismos.

Em algumas amostras foram detectadas a presença de peróxido, o qual foi comprovado pelo aparecimento de uma coloração marrom. O teste consistiu em adicionar ao leite detergente e em seguida adicionar algumas gotas de iodeto de potássio. O peróxido de hidrogênio sofre decomposição gerando gás oxigênio. Essa reação não é instantânea, mas foi acelerada com adição de iodeto de potássio à mistura.

A análise de acidez teve o objetivo de quantificar o ácido lático presente no leite, conhecendo-se, assim, o estado de conservação do leite. Segundo Oliveira (1996), a acidez do 
leite pode variar de $0,13 \%$ a $0,23 \%$, com um teor normal de $0,16 \%$ a $0,18 \%$, sendo responsáveis por essa acidez os fosfatos, citratos, caseínas, albumina e dióxido de carbono dissolvido. O parâmetro acidez foi avaliado por meio de titulação através de graus Dornic, os quais ainda são bastante utilizados pelas miniusinas de laticínios, principalmente devido à facilidade e rapidez na sua execução. Os resultados obtidos para acidez indicam que provavelmente houve falta de higienização durante a obtenção do leite.

No teste de formol, a floroglucina reagiu com o radical formaldeído produzindo uma reação com a coloração salmão, indicando positividade para fraude por adição de formol. $\mathrm{O}$ uso do hidróxido de sódio serve para conferir $\mathrm{pH}$ alcalino, indispensável para que ocorra a reação. Foi identificado formol em duas amostras de leite.

Após elaboração dos procedimentos experimentais, estes foram levados para demonstração em salas de aulas das escolas selecionadas.

\section{b) Em sala de aula}

As turmas foram divididas em cinco grupos de três alunos cada. Cada grupo construiu os equipamentos a serem utilizados no ensaio experimental, utilizando os materiais alternativos já citados. Após, os alunos fizeram as análises físico-químicas tais como, teste de amido, peróxido, formol, ácido e também isolaram as principais proteínas do leite. Os alunos também extraíram a antocianina da flor da papoula e utilizaram como indicador de ácido e base. Os estudantes também determinaram a densidade do leite, de acordo com metodologia descrita na literatura (FREITAS FILHO et al., 2009).

\section{IV - Elaboração e divulgação de jornal e cartilha informativa}

Foram elaboradas cartilhas informativas, Figura 3 abaixo, que foram distribuídas e comentadas nas escolas escolhidas para campo de estudo, na comunidade em que a escola estava inserida e em eventos científicos, como Feiras de Ciências, Bancadas de Ciências e Encontros de Extensão Universitária.

A ideia desta cartilha foi reunir informações relacionadas ao consumo e comercialização do leite in natura, com o objetivo de facilitar o acesso à informação técnica, através do uso de uma linguagem mais acessível. A cartilha visou orientar e conscientizar os 
estudantes e comunidades em geral através de conceitos, informações e procedimentos relacionados ao consumo de leite.

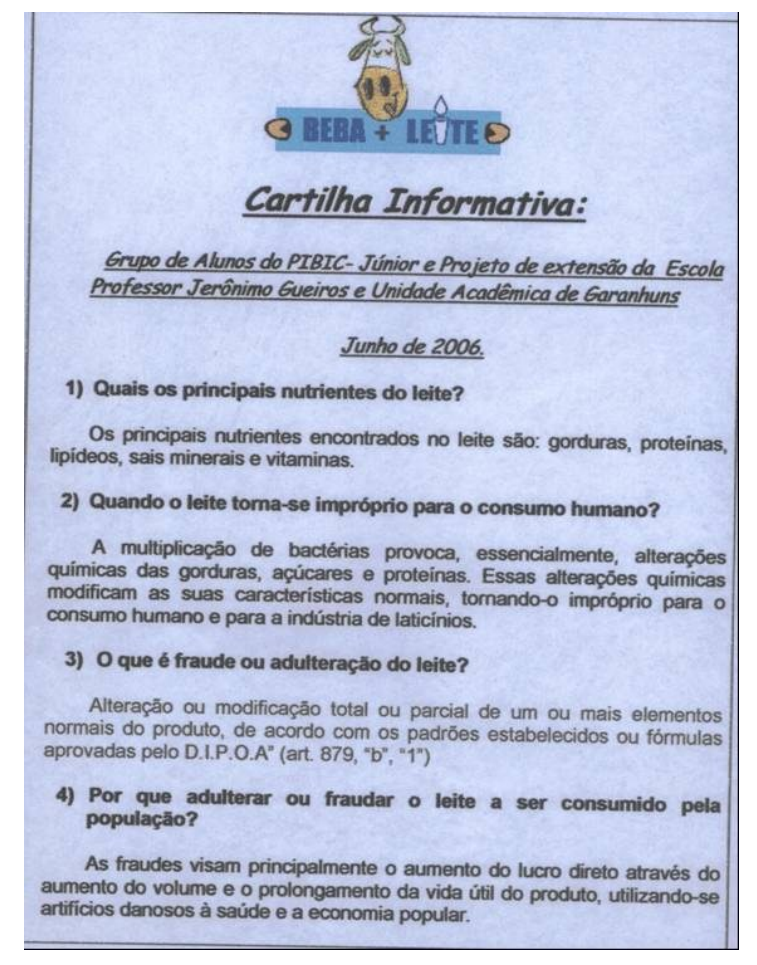

Figura 3: Cartilha Informativa

Jornais impressos também foram elaborados quinzenalmente e distribuídos aos alunos, comunidade em geral e em eventos científicos. Vejamos um exemplar do jornal impresso na Figura 4 abaixo. 


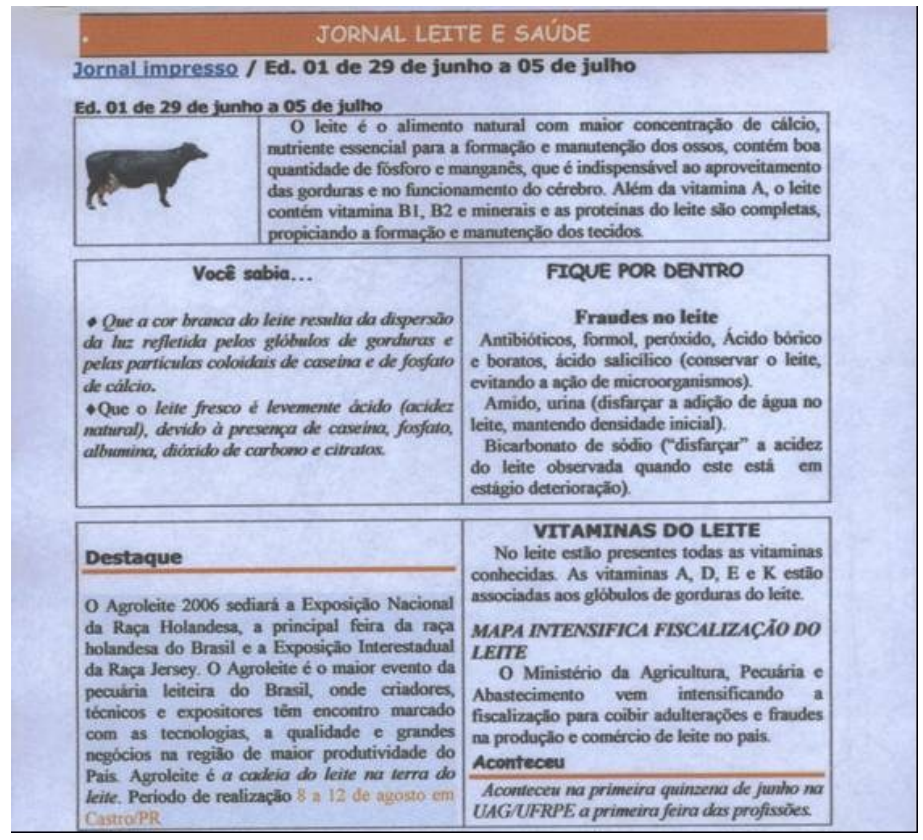

Figura 4: Exemplar do Jornal Impresso

A qualidade do jornal impresso causou impacto na comunidade escolar e moradores da cidade de Garanhuns - PE. As imagens e os textos abordando o que foi realizado nas aulas anteriores foram elementos indispensáveis para o sucesso do jornal. Enfim, os participantes se viram representados e o jornal legitimou o projeto e ajudou as pessoas a entenderem a importância de um leite de boa qualidade na alimentação diária. A distribuição dos 200 exemplares do jornal, quinzenalmente, foi feita no dia a dia das atividades e pelos alunos extensionistas. Eles distribuíram o jornal nas escolas, para os vizinhos; entregavam exemplares na padaria, nas mercearias, no posto de saúde, na igreja e nas associações de bairros.

Com duas páginas, o jornal trazia na capa a principal atividade realizada, geralmente uma matéria positiva, com fotos.

Os jornais e a cartilha foram peças importantes na comunicação do projeto, e o objetivo a ser alcançado era uma maior mobilização em torno dele.

Segundo depoimento de um aluno X, "o jornal e a cartilha ajudaram as pessoas a entender a importância do consumo de leite de boa qualidade”. 


\section{CONSIDERAÇÕES FINAIS}

Sabe-se que o consumo de leite e derivados cresce no mundo todo, inclusive no Brasil, tendo por isso impacto na economia mundial, e o controle da qualidade físico-química do leite é essencial para garantir o bem-estar da população. Assim, é importante detectar problemas na produção do leite e também acusar adulterações no produto. Um leite pode ser considerado fraudado ou falsificado quando não corresponder a um limite de diferença ou acusar presença de substâncias estranhas.

Com a realização do projeto nas escolas selecionadas e a utilização de materiais de baixo custo e de fácil aquisição foi possível realizar experimento para detecção de substâncias estranhas presentes no leite consumido pela população de Garanhuns e também conscientizar alunos, gestores e comunidade em geral da importância de consumir produto de boa qualidade.

Ao realizar experimentos simples com leite — teste de peróxido, formol, ácido, amido etc. - , os estudantes puderam observar casos de fraudes em algumas amostras. As fraudes mais generalizadas foram a adição de água ao leite, constatada pela redução da densidade, e água oxigenada, identificada pela adição de iodeto de potássio ao soro. A legislação brasileira não permite adição de água, água oxigenada, formol e soda cáustica, entre outros.

Os resultados da pesquisa experimental foram divulgados em escolas e na comunidade em geral, através de cartilha informativa e jornais impressos.

Apesar de o leite se constituir em um alimento tão comum, ainda se faz necessário conscientizar os estudantes e população em geral do importante beneficio que este alimento oferece, quando ele é comercializado dentro dos padrões de qualidade.

\section{REFERÊNCIAS}

BEHMER, M. L. A. Tecnologia do Leite. 15a . ed. São Paulo: Livraria Nobel, 1984.

. Tecnologia do leite: Produção, industrialização e análise. $13^{\mathrm{a}}$ ed. São Paulo, 1999.

CARVALHO, B. M. A. et al. Métodos de detecção de fraude em leite por adição de soro de queijo. Revista electrónica de Veterinária, v. 8, n. 6, 2007.

EGITO, A. S. et al. Método eletroforético rápido para detecção da adulteração do leite caprino com leite bovino. Arq. Bras. Med. Vet. Zootec., v. 58, n. 5, p. 932-939, 2006. 
FREITAS FILHO, J. R, et al. Avaliação do teor de caseína e albumina no leite de vacas da raça Girolanda. Revista Brasileira de Tecnologia Agroindustrial. Vol.3, No. 1, 2009.

LISBOA, J. C. F.; BOSSOIANI, M. Experiências Lácteas. Química Nova na Escola. n. 6, 1997.

OLIVEIRA, A. J. Leite. Piracicaba: FEALQ, 1996.

PEDRAS, M. M. Avaliação de propriedades físico-químicas e funcionais de leite processado por tecnologia de homogeneização a ultra alta pressão. 2007. p. 153. Dissertação (Mestrado em Tecnologia de Alimentos) - Universidade Estadual de Campinas, Campinas, SP.

PEREIRA, D. B. C. et al. Físico-química do leite: Métodos Analíticos. Juiz de Fora: Gráfica Oficina de Impressão, 2001.

PINA, M. S. L. et al. Técnicas experimentais para identificação de substâncias estranhas presentes no leite de vaca comercializado em Garanhuns. Revista Química no Brasil. 2007

ORDÓÑEZ, J. A. Tecnologia de alimentos: alimentos de origem animal. Traduzido por MURAD, F. Porto Alegre: Artmed. v. 2, 2005

SILVA, P. H.F. Leite: Aspectos de Composição e Propriedades. Química Nova na Escola. n. 06, 1997.

SILVA, P.H.C. et al. Avaliação físico-química de diversos tipos de leites pasteurizados comercializados no Distrito Federal e adequação aos regulamentos técnicos. Disponível: $<$ http://www.sovergs.com.br/conbravet2008/anais/cd/resumos/R0519-1.pdf $>$. Acesso em: 9 nov. 2009.

SOARES, P.V. Estimativa rápida da carga de microrganismos psicrotróficos em leite cru refrigerado. 2004. 68 p. Dissertação (Mestrado) - Faculdade de Ciências Agrárias e Veterinárias, Universidade Estadual Paulista, Jaboticabal, 2004.

SOARES, E.C.; RAMOS, A.L.S.; RAMOS, E.M. Efeitos de diferentes concentrações de soro nas características físico-químicas de leite cru. In: Seminário de Iniciação Científica (COMPEX), 9, 2005. 